\title{
Information needs of post myocardial infarction patients in Oman
}

\author{
Rashid Said Almamari ${ }^{\mathrm{a}}$, Eilean Rathinasamy Lazarus ${ }^{\mathrm{b}, *}$, Joshua Kanaabi Muliira ${ }^{\mathrm{b}}$ \\ ${ }^{a}$ Sultan Qaboos University Hospital, Sultan Qaboos University, Oman \\ ${ }^{\mathrm{b}}$ Department of Adult Health and Critical Care, College of Nursing, Sultan Qaboos University, Muscat, 123, Oman
}

\section{Introduction}

According to the World Health Organization (WHO), the prevalence of non-communicable diseases worldwide has been increasing, and among these, cardiovascular diseases (CVDs) are one of the most serious and leading cause of mortality and morbidity. ${ }^{1}$ CVDs are responsible for almost half of all the deaths worldwide and majority of these deaths occur in low-to-middle-income countries and among people aged 70 years and above, and 15 years and above due to obesity. ${ }^{2}$ Acute myocardial infarction (AMI) is a critical health problem because it can quickly lead to death or leads to serious post-acuteperiod complications. ${ }^{3,4}$ Myocardial infarction (MI) is a life-threatening condition and global trends show that there is a significant increase in its prevalence in both developed and developing. The precursors of MI such as coronary heart disease (CHD) are also reported among the leading causes of mortality and morbidity in developed countries and developing countries. ${ }^{5,6}$

A systematic review of 14 published studies was performed to examine information needs of post-MI patients and their families, 6 of these studies used the same instrument. The results showed that overall, information needs about risk factors was rated as the most important domain, followed by information needs on medications, anatomy and physiology, and physical activity. The information needs about miscellaneous, diet, psychological factors, and the CCU, ranked lower. ${ }^{7}$

Another study conducted in Norway reported that it is very important to assess the current provision of in-hospital information and education among AMI patients. ${ }^{22}$ Patients before discharge reported that information needs specifically related to medications and problems in daily-life activities that they may encounter after being discharged home are very important. Bailey conducted a descriptive, comparative study in the United States to explore the differences between patients' and nurses' perceptions of cardiac patients' information needs. The study was conducted in a private community hospital in a North Florida hospital, and 20 nurses and 20 post-Coronary Artery Bypass Graft (CABG) patients were recruited. The researcher used the CPLNI tool to measure cardiac information needs. The findings showed that the patients and their nurses perceived medication information as the highest information need. Both patients and nurses perceived that physical activities were the least important to them. ${ }^{23}$
In Oman, the overall incidence rate of Acute Coronary Syndrome (ACS) is estimated at 338.9 per 100,000 person years and cases of unstable angina (55\%), ST Elevation (26\%), and Non-ST Elevation (19\%), are very common. ${ }^{6}$ The prevalence rate of MI in Oman is $0.0034 \%$ among Omanis. ${ }^{8,9}$ This shows that CVDs and associated psychosocial sequels are a major health problem in Oman. ${ }^{10,11}$ This increasing prevalence, morbidity and mortality could be due to lack of adequate information to ensure prevention of complications, adequate self-care and prevention of re-infarction. It has been reported that postMI patients without adequate pre-discharge education tend to present with many complications, recurrent attacks, and readmissions, ${ }^{12}$ which put an additional economic burden on the family and health care system. ${ }^{13}$

Education and cardiac rehabilitation after MI are very important strategies for improving patients' survival, recovery, and quality of life. ${ }^{14}$ It is essential that post-MI patients have adequate information about their condition and the needed self-care because they are at a higher risk of developing another attack, especially those who have risk factors such as smoking, hypertension, hyperlipidemia, obesity, and lack of exercise. Therefore, it is important to explore the information needs of post-MI patients because the findings can provide us with the baseline data needed to design effective pre-discharge education interventions. The purpose of the current study was to assess the information needs of post-MI patients attending cardiology outpatient clinics in selected tertiary hospitals in Oman. The study was guided by the following specific objectives:

1. To assess the information needs of post-Myocardial Infarction patients and

2. To assess the association between demographics variables and information needs of post- Myocardial Infarction patients.

\section{Methods}

A cross-sectional design was used to assess the information needs of post-MI patients. The study was conducted at Sultan Qaboos University Hospital (SQUH) and the National Heart Center at Royal Hospital (RH) in Muscat (Oman). The two settings were selected because they are the major government referral tertiary hospitals that specialize in

\footnotetext{
* Corresponding author.

E-mail addresses: rmamari32@gmail.com (R.S. Almamari), eileansrmc@gmail.com (E.R. Lazarus), jkmuliira@gmail.com (J.K. Muliira).
} 
management of heart diseases. The participants were selected from the cardiology outpatient clinics of SQUH and RH. The two hospitals received referrals all the other health care facilities in Oman for further evaluation and treatment cardiac problems and they are the main providers of coronary angiography and CABG surgeries. The sample size was determined using power analysis process (PASS Sample Powerversion 2.0) and from previous studies. ${ }^{8}$ The confidence level of $95 \%$ was used and this yielded the two tailed $\mathrm{z}_{(0.05 / 2)}$ value of 1.96 . The margin of error (ME) was considered and was used to estimate the proportion with the interval of ( \pm ME) $\%$ and often chosen at $8 \%$ and therefore ME is 0.08 .

Informed consent: The participants in this study received a written consent form detailing the scope and the purpose of the study, with clear guidance indicating the research risks and benefits, their right of self-determination, and their right to withdraw at any time freely without any penalty or restrictions. The participants were informed that there were no major risks or harm associated with the study. The participants' questionnaires and written records were kept confidential and were utilized solely for research purposes. The participants' identities were not revealed, and each questionnaire was labeled with a specific study code to maintain privacy and confidentiality. All the data collected from the patients were secured under a lock and key. The participants did not incur costs as a result of participating in this study.

\subsection{Participants}

The participants were patients who were post-MI at least one month ago, attending the Cardiology Outpatient Clinic for follow-up care after discharge from SQUH and RH. A total of 180 post-MI patients were recruited in the study using purposive sampling method. In order to be included in the study the participants had to meet the inclusion criteria of: Omani by nationality; was diagnosed with MI at least one month back; age of 18 years and above; able to understand and speak Arabic or English and free of mental disorders to sign a consent form.

\subsection{Study instrument}

The study measured information needs and demographic characteristics of the post-MI patients (age, gender, level of education, occupation, marital status, smoking habits, and clinical variables such as comorbidities, current medication, body mass index, and exercise). The study questionnaire used for data collection was comprised of the demographic data sheet and the Cardiac Patients Learning Needs Inventory (CPLNI). ${ }^{14}$ The CPLNI measures the information needs in the following domains: introduction to the critical care unit (CCU), anatomy and physiology, psychological factors, risk factors, medication information, diet information, physical activity, and other pertinent information. The participant responds to items under each domain on a 5 -point Likert scale as: not important $=1$; somewhat important $=2$; moderately important $=3$; important $=4$; and very important $=5$. In this study the Arabic version of the CPLNI was used. ${ }^{14}$

The CPNLI consists of 44 items and previous studies it have been reported to have Cronbach alpha coefficient of 0.96 . $^{3}$ Because the setting for the study was the cardiac outpatient clinics, permission was sought from the original author to remove the domain of "Introduction to CCU" and one item of "What to do if I have chest pain?" was moved to the "Anatomy and Physiology" domain. Therefore the modified CPLNI used the study had 38 items with total score ranging from 38 to 190. Pilot testing was conducted to assess readability and patients' understanding of the items. In the current study, the reliability of the modified CPLNI was checked, and the Cronbach's alpha was 0.96. The Cronbach's alpha for all the domains is presented in Table 1. The interpretation of the total scores of the CPLNI was done based on a recent study conducted in Bangladesh. ${ }^{15}$ The means of importance of the level of information needs were classified as low (1-2.33), moderate (2.34-3.66), and high (3.67-5.00).
Table 1

Reliability coefficients of subscales of the modified CPLNI.

\begin{tabular}{ll}
\hline MCLNI & Cronbach's Alpha \\
\hline Anatomy \& Physiology & 0.919 \\
Psychological Factors & 0.912 \\
Risk Factors & 0.915 \\
Medication Information & 0.859 \\
Diet Information & 0.923 \\
Physical Activity & 0.875 \\
Other Pertinent Information & 0.898 \\
Total modified CPLNI & 0.969 \\
\hline
\end{tabular}

\subsection{Data analysis}

The study attempted to answer the following specific research questions: 1) what is the level of information needs among post-MI patients attending cardiology outpatient clinics? and 2) What demographics variables are associated with information needs of post-MI patients attending cardiology outpatient clinics? The data was analyzed using SPSS version 23. Descriptive statistics such as frequency, percentage, mean, standard deviation were used to describe the participant characteristics and the level of perceived information needs. The Chisquare test was used to identify associations between the post MI patients' demographic characteristics and information needs. The significance level for all statistical tests was set at $p \leq 0.05$ (two tailed).

\section{Results}

\subsection{Characteristics of the participants}

A total of 180 participants were included in the study from both hospitals (participant response rate $=99.4 \%$ ). A description of the participants' characteristics is presented in Table 2. The majority of participants were male (68.3\%) and older adults (56.1\%). The average age of the participants was 62 years $(S D=11.3)$. Most of the participants had no formal education (61.7\%), were married (77. $2 \%$ ), and were retired $(40.6 \%)$ or not working $(39.4 \%)$. The majority were also not currently smoking $(91.1 \%)$, overweight $(61.1 \%)$, not doing regular exercises $(68.3 \%)$ and were diagnosed with MI between 0 and 6 months (41.1\%) or 7 and 12 months (42.8\%) ago.

\subsection{Participants comorbidities and medications}

Fig. 1 shows the comorbidities of the participants and the most common were dyslipidemia (78.9\%), coronary artery disease $(77.2 \%)$, hypertension (69.4\%), and diabetes mellitus (58.3\%). As illustrated in Fig. 2, a large number of participants were currently taking medications such as Aspirin (100\%), atorvastatin (93.9\%), atenolol (60\%), clopidogrel (56.1\%), and Lisinopril (58.3\%).

\subsection{Post-MI patient information needs}

The CPLNI was used to assess participants' perceived information needs. The results summarized in Table 3 show that overall the participants reported high levels of information needs, with a sample mean score of $4.66(M=4.66 ; \mathrm{SD}=0.528)$. The majority of participants (93.9\%) had a high-level of information needs (score 3.67-5.00). The results presented in Table 4 shows that the participants had high-level information needs in all of the domains of the CPLNI. However the highest information needs were in the domains of medication information, anatomy and physiology, diet information, and risk factors. Additional analysis using the chi-square test showed that there was a significant relationship between body mass index (BMI) and level of information needs $\left(\chi^{2}=15.22 ; \mathrm{p}=0.002\right)$. The patients with high tended to have much higher overall information needs. 
Table 2

Characteristics of the participants.

\begin{tabular}{|c|c|c|}
\hline Characteristic & Category & $\begin{array}{l}\text { Number of } \\
\text { Participants F (\%) }\end{array}$ \\
\hline \multirow[t]{2}{*}{ Gender } & Male & $123(68.3)$ \\
\hline & Female & $57(31.7)$ \\
\hline \multirow{3}{*}{$\begin{array}{l}\text { Age Group in years }(M=62 ; \\
\quad \mathrm{SD}=11.3)\end{array}$} & $18-40$ & $6(3.3)$ \\
\hline & $41-60$ & $73(40.6)$ \\
\hline & $\geq 61$ & $101(56.1)$ \\
\hline \multirow[t]{5}{*}{ Level of Education } & Non Literate & $111(61.7)$ \\
\hline & Primary & $34(18.9)$ \\
\hline & Secondary & $22(12.2)$ \\
\hline & Degree & $8(4.4)$ \\
\hline & Postgraduate & $5(2.8)$ \\
\hline \multirow[t]{4}{*}{ Marital status } & Single & $4(2.2)$ \\
\hline & Married & $139(77.2)$ \\
\hline & Divorced & $4(2.2)$ \\
\hline & Widow & $33(18.3)$ \\
\hline \multirow[t]{4}{*}{ Occupation } & Formally Employed & $21(11.7)$ \\
\hline & Self-employed & $15(8.3)$ \\
\hline & Retired & $73(40.6)$ \\
\hline & Not working & $71(39.4)$ \\
\hline \multirow{3}{*}{$\begin{array}{l}\text { Monthly Income (R.O) } \\
\qquad(\mathrm{M}=431.3 ; \mathrm{SD}=658)\end{array}$} & $0-400$ & $129(71.7)$ \\
\hline & $400-1000$ & $33(18.3)$ \\
\hline & $\geq 1001$ & $18(10.0)$ \\
\hline \multirow[t]{2}{*}{ Currently smoking } & Yes & $16(8.9)$ \\
\hline & No & $164(91.1)$ \\
\hline \multirow{2}{*}{$\begin{array}{l}\text { If you smoke, how many years has } \\
\text { been smoke? }\end{array}$} & $20-30$ & $12(6.7)$ \\
\hline & $\geq 35$ & $4(2.2)$ \\
\hline$M=27.4 \pm 8.93$ & NA & $164(91.1)$ \\
\hline Time since diagnosis (Months) & $0-6$ & $74(41.1)$ \\
\hline \multirow[t]{2}{*}{$M=10.55 \pm 7.58$} & $7-12$ & $29(16.1)$ \\
\hline & $\geq 13$ & $77(42.8)$ \\
\hline Body Mass Index (BMI) & Underweight $(\leq 19.5)$ & $9(5.0)$ \\
\hline \multirow[t]{2}{*}{$M=26.9 \pm 4.8$} & Normal (19.6-25.5) & $61(33.9)$ \\
\hline & Overweight $\geq 25.6$ & $110(61.1)$ \\
\hline \multirow[t]{2}{*}{ Exercise } & Yes & $57(31.7)$ \\
\hline & No & $123(68.3)$ \\
\hline
\end{tabular}

\section{Discussion}

To our knowledge and according to available published literature this is the first study to report about post-MI patient information needs in Oman. The general characteristics of the sample (demographic characteristics and comorbidities) included in the study are very similar to those of other post-MI patients reported by other studies. Literature shows that the main risk factors for MI are aging, male gender, smoking, and comorbidities. ${ }^{14,17}$ The majority of participants in the current study were older adults, male, overweight or obese, not engaged in regular physical activity, and had underlying comorbidities representing different aspects of the metabolic syndrome. Although self-report of being a current smoker was not a common status, the majority of participants had been smoking before their MI for a long time and had quit. The above highlight show that the risk for MI and other cardiovascular diseases was still very high among the post-MI patients, ${ }^{18}$ and therefore the study purpose of exploring their information needs was relevant.

The main results of the study have showed that post-MI patients attending cardiology outpatients clinic for follow up care in Oman have high information needs in multiple domains and those of key concern include medication information, anatomy and physiology, diet information, and risk factors. Previous studies have also reported that post-MI patients tend to have high information need about medication information. ${ }^{(14,15,16,19)}$ Many time post-MI patients want to know more about the medications they are taking and its indications, dosages, and side effects in order to overcome any issues related to noncompliance. $^{16}$

Similarly, other studies have also showed that post-MI patients report high information needs related to anatomy and physiology to be a high-level information need. ${ }^{16,19,20}$ Our study findings are congruent with these reports. There are also some studies which have found only moderate-level information needs related to anatomy and physiology. ${ }^{14,20}$ These findings are not surprising because many times in order for the patient to understand the MI disease process, they need to understand the basic structure of the heart, how it works, and what happens to heart muscles during an MI incidence. The finding of this study related to diet showing high information need is also consistent with previous studies. ${ }^{14,16,19,20}$ In many emerging economies people living sedentary lifestyles and are consuming unhealthy diet and this is fueling the epidemiological transition to non-communicable diseases such as cardiovascular diseases. ${ }^{16}$ It is therefore not surprising that individuals already diagnosed with MI would perceive a need for more information about diet and other aspects.

The participants' perceived need for other information and information related to psychological factors was high and this is consistent with previous studies ${ }^{16,19,20 .}$. However a study of Jordanian postMI patients showed a moderate-level information need related to psychological factors. ${ }^{14}$ Like in other studies, the participants in the current study felt that information needs related to physical activity were

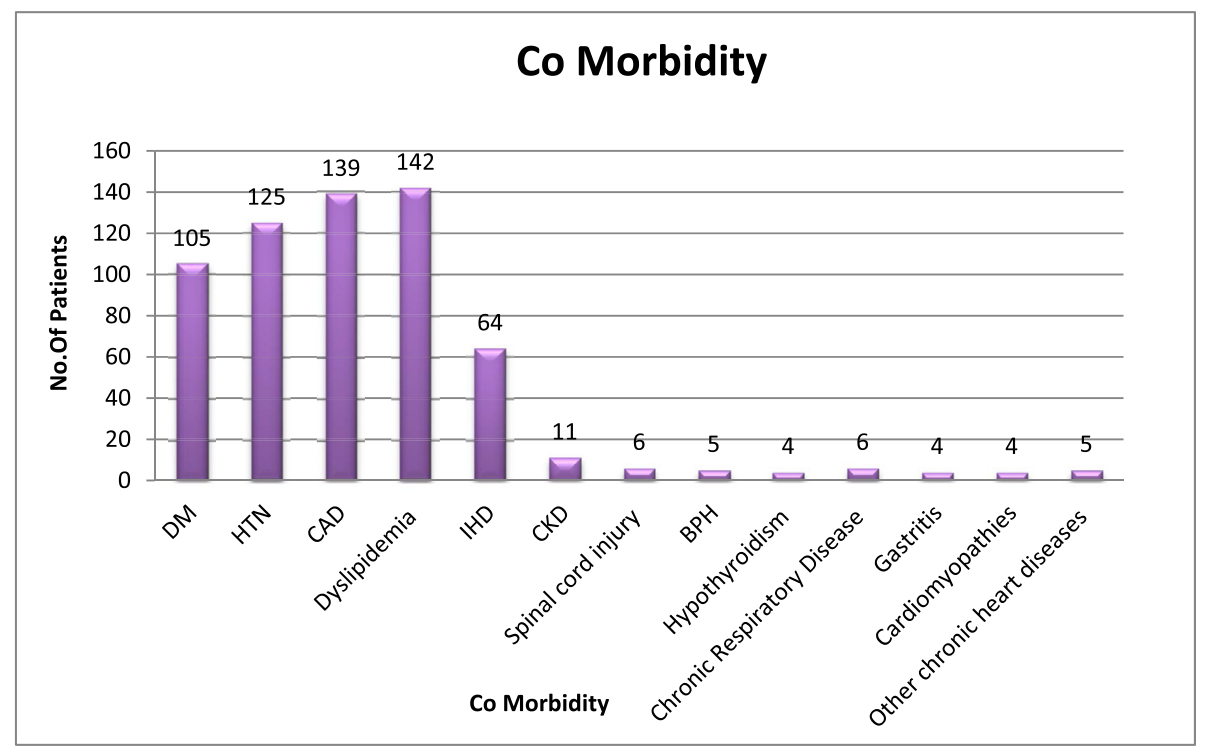

Fig. 1. Common Comorbidities of post MI patients $(\mathrm{N}=180)$. 


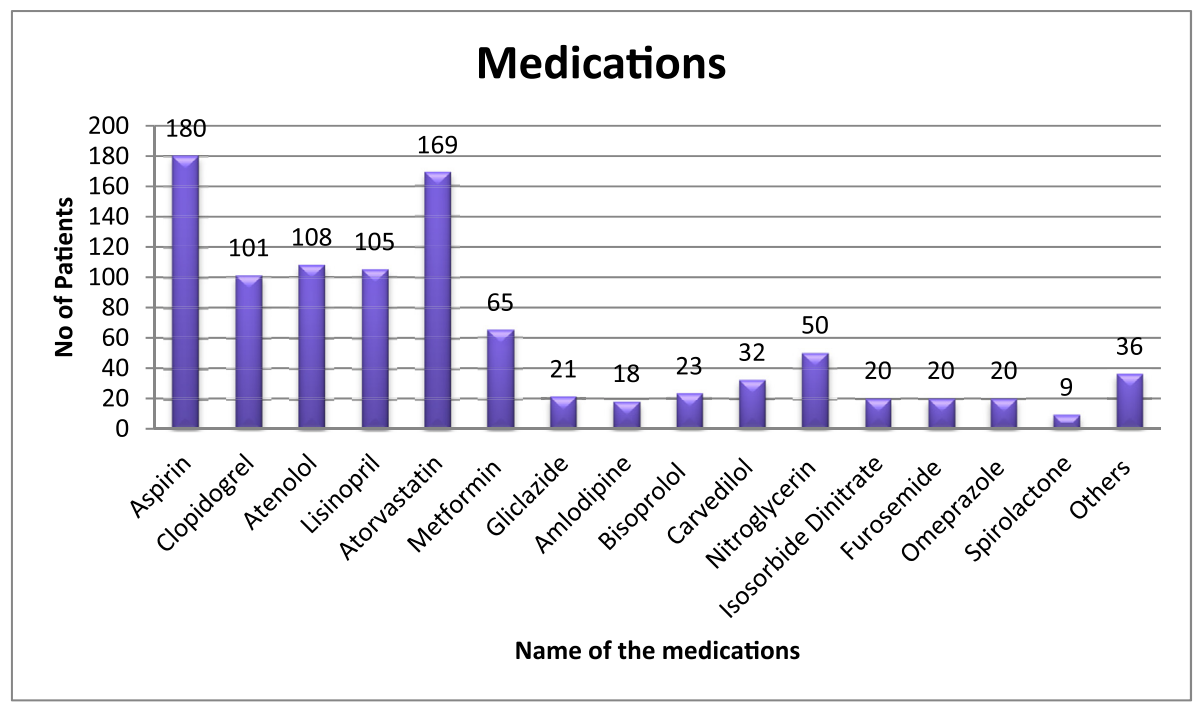

Fig. 2. Participants' current medications $(\mathrm{N}=180)$.

Table 3

Frequency and percentage of the patients classified by the level of information needs of patients Post-MI $(\mathrm{N}=180)$.

\begin{tabular}{llll}
\hline Level of information needs & Possible score & $N=180$ & $\%$ \\
\hline Low & $1-2.33$ & 1 & 0.6 \\
Moderate & $2.34-3.66$ & 10 & 5.6 \\
High & $3.67-5.00$ & 169 & 93.9 \\
\hline
\end{tabular}

$\mathrm{M}=4.66, \mathrm{SD}=0.528, \mathrm{Min}-\mathrm{Max}=1.5-5.0$.

Table 4

Mean, Standard Deviation, and Level of Information Needs for each subscale of the CPLNI $(\mathrm{N}=180)$.

\begin{tabular}{llll}
\hline $\begin{array}{l}\text { Cardiac Patient } \\
\text { Learning Needs } \\
\text { Inventory Subscales }\end{array}$ & $\begin{array}{l}\text { Mean of total } \\
\text { score } \\
\text { M (SD) }\end{array}$ & $\begin{array}{l}\text { Weighed Mean of } \\
\text { importance M } \\
\text { (SD) }\end{array}$ & $\begin{array}{l}\text { The level of } \\
\text { information } \\
\text { needs }\end{array}$ \\
\hline $\begin{array}{l}\text { Anatomy and } \\
\quad \text { Physiology }\end{array}$ & $33.41(4.29)$ & $4.77(0.612)$ & High \\
$\begin{array}{l}\text { Psychological Factors } \\
\text { Risk Factors }\end{array}$ & $22.80(4.07)$ & $4.56(0.815)$ & High \\
Medication Information & $18.83(2.52)$ & $4.70(0.630)$ & High \\
Diet Information & $19.36(1.72)$ & $4.84(0.430)$ & High \\
Physical Activity & $28.37(3.64)$ & $4.72(0.608)$ & High \\
Other Information & $22.22(3.88)$ & $4.44(0.776)$ & High \\
Total learning needs & $32.39(4.53)$ & $4.62(0.647)$ & High \\
$\quad$ score & $177.4(20.0)$ & $4.66(0.528)$ & High \\
& & &
\end{tabular}

not as high as other aspects. ${ }^{16,19}$ This finding has implication since in Oman the prevalence of chronic diseases in Oman is increasing and physical inactivity is the fourth commonest reason for chronic disease in Oman. ${ }^{21}$

\section{Implication for practice}

The results of this study have implication for follow-up and rehabilitation care of post-MI patients as mentioned in the other international studies. The results show that post-MI patients have high information needs in all aspects such as medication, anatomy and physiology, diet and risk factors This may be an indication that even after post-MI diagnosis and follow-up care in the cardiology outpatient clinics the patients are not fully informed about the medication, MI disease process, needed diet and risk factors for the disease. This situation increases the risk of new MI, cardiac events and complications of heart disease. Therefore this study informs the nurses and healthcare providers caring post-MI patients that:

- Post-MI patients continue to have high information needs after discharge from the hospital and while receiving follow-up care

- Post-MI patients need to be need deliberately assessed to determine their information needs during follow up care in order to promote adequate and self-care.

- Deliberate patient education needs to be an integral and essential part of cardiac rehabilitation program and cardiology follow up clinic as a way of meeting patient information needs.

\section{Limitations of the study}

The post-MI patients' information need was assessed at a single point in time. The findings showed only perceived information after discharge; the study did not explore information needs before discharge, patient self-care practices, and knowledge about the disease to validate information needs.

\section{Conclusion}

The findings of the study can be used to guide clinical nurse specialists, patients and family education link nurses in hospitals to concentrate on perceived information needs. Based on this, structured teaching programs can be utilized before and after discharge and during follow-up visits. Ultimately, this can improve patients' quality of care and outcomes, and can reduce readmission and costs, improve the quality of life. This study will also be a resource for future research studies in this field.

\section{Conflicts of interest}

All the authors declare no conflict of interest.

\section{Ethical consideration}

Ethical approval to conduct the study was obtained from the Research and Ethics Committee of the College of Nursing at Sultan Qaboos University; Medical Research Ethics Committee, College of Medicine and Health Sciences at Sultan Qaboos University; and Research and Ethical Review and Approve Committee, Ministry of Health. 


\section{References}

1. Aldoori NM. Prevalence of obesity among female adolescents in al-hillah city: future risk of cardiovascular diseases. Res J Pharm Technol. 2017;10(7):2127-2131.

2. Keats AK, Mocumbi AO, Ntsekhe M, Sliwa K, et al. Cardiovascular disease in Africa: epidemiological profile and challenges. Nat Rev Cardiol. 2017;14:273.

3. Uysal H, Enç N. A Turkish version of the cardiac patients' learning needs inventory; patient questionnaire (TR-CPLNI): reliability-validity assessment. Int J Caring Sci. 2012;5:264-279.

4. Molazem Z, Rezaei S, Mohebbi Z, et al. Effect of continuous care model on lifestyle of patients with myocardial infarction. ARYA Atheroscler. 2013;9:186.

5. Aminpour S, Shahamfar M, Shahamfar J. Effects of lifestyle modification program in reduction of risk factors in patients with coronary heart disease. Eur J Exp Biol. 2014:4:353-357.

6. Alkubati SA, Al-Zaru IM, Khater W, Ammouri AA. Perceived learning needs of Yemeni patients after coronary artery bypass graft surgery. $J$ Clin Nurs. 2013;22:930-938.

7. Scott JT, Thompson DR. Assessing the information needs of post-myocardial infarc tion patients: a systematic review. Patient Educ Counsel. 2003;50(2):167-177.

8. Al-Lawati J, Sulaiman K, Panduranga P. The epidemiology of acute coronary syndrome in Oman: results from the Oman-RACE study. Sultan Qaboos Univ Med J. 2013;13:43.

9. Al-Mawali A. Non-communicable diseases: shining a light on cardiovascular disease, Oman's biggest killer. Oman Med J. 2015;30:227.

10. Gu G, Zhou Y, Zhang Y, et al. Increased prevalence of anxiety and depression symptoms in patients with coronary artery disease before and after percutaneous coronary intervention treatment. BMC Psychiatry. 2016;16:259.

11. Jackson AM, McKinstry B, Gregory S, et al. A qualitative study exploring why people do not participate in cardiac rehabilitation and coronary heart disease self-help groups, and their rehabilitation experience without these resources. Prim Health Care
Res Dev. 2012;13:30-41.

12. Rodriguez JB, Acharya $\mathrm{P}$, Olson E, et al. Risk factors for 30-day readmissions after acute myocardial infarction. ICF J. 2015;4:30-36.

13. Kolansky DM. Acute coronary syndromes: morbidity, mortality, and pharmacoeconomic burden. Am J Manag Care. 2009;15:36-41.

14. Hamdan FR, AlMomani I. Jordanian nurses and acute myocardial infarction patients perceptions about learning needs. Glob J Med Phys Health Educ. 2015;3:85-99.

15. Gerard PS, Peterson LM. Learning needs of cardiac patients. Cardiovasc Nurs. 1984;20:7

16. Sultana R. Patients' Discharge Information Needs and Nurses' Discharge Information Support Regarding Myocardial Infarction in Bangladesh Doctoral dissertation Bangladesh: Prince of Songkla University; 2014.

17. Morton PG, Fontaine DK. Critical Care Nursing: A Holistic Approach. first ed. London: Lippincott Williams \& Wilkins; 2013:1408-1418.

18. Li Y, Rukshin I, Pan F, et al. The impact of the 2008-2009 economic recession on acute myocardial infarction occurrences in various socioeconomic areas of Raritan bay region, New Jersey. N Am J Med Sci. 2014;6:215.

19. Bailey J. Patient and Nurses' Perceptions of the Cardiac Patient's Learning Needs. Doctoral Dissertation Master Thesis Florida, USA: The Florida State University School of Nursing; 2004

20. Jaworski CA. Inpatient Education: Are Patients Perceived Learning Needs Met Following First MI? USA: Doctoral dissertation, University of Toledo; 2005

21. Mabry R, Owen N, Eakin E. A national strategy for promoting physical activity in Oman: a call for action. Sultan Qaboos Univ Med J. 2014;22:1-6.

22. Oterhals K, Hanestad BR, Eide GE, Hanssen TA. The relationship between in-hospital information and patient satisfaction after acute myocardial infarction. Eur $J$ Cardiovasc Nurs. 2006;5(4):303-310.

23. Baily J. Patient and Nurse Perception of Cardiac Learning Needs Master Thesis The Florida State University School of Nursing; 2004 